\title{
Hypopharyngeal cancer treatment based on definitive radiotherapy: who is suitable for laryngeal preservation?
}

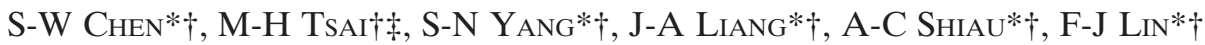

\begin{abstract}
Aims: To investigate prognostic factors for survival and locoregional control in patients with stage IIVA hypopharyngeal cancer treated with laryngeal preservation radiotherapy.

Methods: This study was a retrospective analysis of 108 patients with stage I-IVA squamous cell carcinoma of the hypopharynx, treated with laryngeal preservation radiotherapy. Actuarial survival, disease-specific survival and local relapse-free survival were calculated, and multivariate analyses were performed using Cox's proportional hazards model.

Results: After a median follow-up duration of 39 months, the five-year local relapse-free survival rate was 35 per cent for all patients, 66 per cent for those with stage I-II disease, 46 per cent for those with stage III disease and 20 per cent for those with stage IVA disease $(p=0.004)$. Multivariate analyses showed that tumour and node stages were independent prognostic factors.

Conclusions: Patients with stage I-II disease were suitable for laryngeal preservation radiotherapy. For most patients with stage III-IVA disease, other than those who were $\mathrm{T}_{1} \mathrm{~N}_{1}$ or $\mathrm{T}_{2} \mathrm{~N}_{1}$, the treatment results were poor.
\end{abstract}

Key words: Pharynx Neoplasms; Carcinoma; Radiotherapy; Prognosis

\section{Introduction}

For patients with hypopharyngeal carcinoma (HPC), treatment decisions are complex and include such considerations as tumour stage and location, patient condition, and individual preference.

Radiotherapy (RT) allows preservation of laryngeal function, and the selection criteria for RT are similar to and have been based primarily on the protocol for laryngeal cancer. Traditionally, HPC patients at tumour $(\mathrm{T})$ stage $\mathrm{T}_{1}$ or $\mathrm{T}_{2}$ have been treated with $\mathrm{RT}$ for laryngeal preservation.

In contrast, $\mathrm{T}_{3}$ or $\mathrm{T}_{4}$ lesions are considered unfavourable for RT, and there is considerable controversy regarding their optimum treatment. Some published studies have reported that patients treated with primary RT and salvage surgery showed an overall five-year survival rate of less than 20 per cent. ${ }^{1,2}$ Total laryngectomy, combined with neck lymph node dissection, is often recommended for these patients. Curative RT with surgical salvage in reserve is also an accepted protocol.

Overall, the results of salvage surgery following RT failure have been unsatisfactory. ${ }^{2-4} \mathrm{~A}$ significant number of RT failures cannot be salvaged with surgery, either because of the late diagnosis or the patient's refusal to undergo subsequent surgery.

In addition, for patients who are anatomically unsuitable or medically unfit for surgery, concurrent chemoradiotherapy or RT alone are always suggested. There is no available prospective study to demonstrate which treatment is better.

However, the survival and local control rates for advanced HPC have been shown to be inferior to those for laryngeal cancer. ${ }^{5}$ Better patient selection is needed in order to optimise treatment outcomes regarding larynx preservation. Better patient selection would also enable a more accurate discussion of the value of surgery and RT for local control, during the consent process. Furthermore, improved patient selection may help to determine those patients with advanced tumours who should receive more aggressive, combined modality treatment.

Patients who choose definitive RT for laryngeal preservation should be informed of the appropriate treatment options, and of each option's probability of cure. This retrospective study evaluated the prognostic factors for survival and locoregional control in patients with stage I-IVA HPC treated with

From the Departments of *Radiation Therapy and Oncology, and of $\ddagger$ Otorhinolaryngology, and the $†$ School of Medicine, China Medical University, Taichung, Taiwan.

Accepted for publication: 25 June 2007. First published online 12 October 2007. 
curative-intent laryngeal preservation RT. In order to clarify the role of laryngeal preservation RT in patients with stage III disease, further analysis was conducted by stratification of these patients. In addition, we also compared the treatment outcomes of patients with stage III-IVA lesions who had been treated with and without a combination of chemotherapy with RT.

\section{Materials and methods \\ Patients}

From January 1996 to June 2005, 108 patients with stage I-IVA squamous cell carcinoma of the hypopharynx were enrolled in this retrospective analysis. The enrolment criteria were as follows: firstly, patients who had completed the allocated RT treatment and were followed up for a minimum of one year or until death; secondly, patients whose tumour was staged, following a comprehensive physical examination, laryngoscopy, tumour biopsy, chest radiograph, neck computed tomography (CT) scan, abdominal ultrasonography and bone scan; and thirdly, patients who were known to have no evidence of distant metastasis, after pretreatment image studies.

Stage IVB tumours are technically unresectable. The treatment of these patients was considered to be palliative, and they were excluded from analysis.

There was no intentional combined surgery following definitive RT. The age of the patients ranged from 32 to 84 years, with a median of 57 years. There were 105 men and three women. The sites of tumour involvement were determined mainly from laryngoscopy findings; all involved sites were recorded. The pyriform sinus was the principal site of involvement in 103 cases. For tumours involving both the posterior pharyngeal wall and the pyriform sinus, no attempts were made to differentiate tumour origin. Neck lymph nodes were considered pathological when their smallest axis diameter was $>1 \mathrm{~cm}$ on CT scan. The patient characteristics and distribution of tumour-node-metastasis (TNM) classification are listed in Tables I and II.

\section{Treatment}

Seventy-six patients were treated by conventional RT and 32 by a sequential intensity-modulated technique. All patients received $1.8 \mathrm{~Gy}$ daily up to a total dose of 68.4-82.4 Gy (median 70.2 Gy).

Patients receiving conventional treatment were initially treated with 46.8 Gy to bilateral opposing fields and one anterior low-neck field, including the skull base and whole neck lymphatic drainage. Primary tumours were further boosted to $70.2 \mathrm{~Gy}$ with exclusion of the spinal cord. Bilateral neck lymphatics were boosted with electron beams of appropriate energy. The nodal doses were $70.2 \mathrm{~Gy}$ for clinically positive nodes and 55.8-59.4 Gy for clinically negative nodes. The RT dose was prescribed at midpoint (bilateral opposing field), with a depth of 3-4 cm (low anterior neck field) or 85-90 per cent depth dose (for electron beam).
TABLE I

PATIENT CHARACTERISTICS*

\begin{tabular}{lc}
\hline Age (median; years) & $32-84(57)$ \\
Gender & $\mathrm{M}=105 ; \mathrm{F}=3$ \\
Pathology & 61 \\
WD or MD SCC & 16 \\
PD SCC & 31 \\
Unclassified SCC & \\
Stage & 13 \\
I-II & 39 \\
III & 56 \\
IVA & \\
Performance status (ECOG) & 96 \\
$0-1$ & 12 \\
2-3 & \\
Trachestomy? & 88 \\
No & 20 \\
Yes & \\
Dysphagia score & 86 \\
0-1 & 22 \\
2-3 & $64.8-73.8(70.2)$ \\
Radiation dose (median; Gy) & $42-110(60)$ \\
Treatment duration (median; days) & \\
Concurrent chemotherapy? & 52 \\
Yes & 56 \\
No & \\
Induction chemotherapy? & 34 \\
Yes & 74 \\
No & $14-120(39)$ \\
Median follow up (median; months) & \\
\hline
\end{tabular}

Data represent number of patients unless otherwise specified. $*$ Total $=108$ patients. $\mathrm{M}=$ male; $\mathrm{F}=$ female; $\mathrm{WD}=$ well differentiated; $\mathrm{MD}=$ moderately well differentiated; $\mathrm{SCC}=$ squamous cell carcinoma; PD $=$ poorly differentiated; $\mathrm{ECOG}=$ eastern cooperative oncology group

For patients treated with intensity-modulated technique, the gross tumour volume included the primary tumour and involved lymph nodes of more than $1 \mathrm{~cm}$ in diameter on CT imaging. Clinical target volume modelling considered two regions of different risk. The clinical target volume one region encompassed the gross tumour volume and the regions adjacent to the gross tumour. The clinical target volume two region consisted of ipsilateral or contralateral elective nodal regions at risk of harbouring microscopic tumour. The planning target volume consisted of a $3 \mathrm{~mm}$ margin in all directions around the clinical target volume. The dose delivered to the clinical target volume one and clinical target volume two during the first course was $54 \mathrm{~Gy}$ $(1.8 \mathrm{~Gy} \times 30 \mathrm{Fr})$, and the clinical target volume one region was boosted a further $16.2 \mathrm{~Gy}$ $(1.8 \mathrm{~Gy} \times 9 \mathrm{Fr})$ during the second course. Thus, the cumulative dose to the clinical target volume one

TABLE II

DISTRIBUTION OF PATIENTS' TNM STAGING

\begin{tabular}{lrrrrr}
\hline N stage & \multicolumn{4}{c}{ T stage $(n)$} & Total $(n)$ \\
\cline { 2 - 5 } & $\mathrm{T}_{1}$ & \multicolumn{1}{c}{$\mathrm{T}_{2}$} & $\mathrm{~T}_{3}$ & $\mathrm{~T}_{4 \mathrm{a}}$ & \\
\hline $\mathrm{N}_{0}$ & 2 & 11 & 21 & 11 & 45 \\
$\mathrm{~N}_{1}$ & 1 & 9 & 8 & 8 & 26 \\
$\mathrm{~N}_{2}$ & 0 & 4 & 17 & 16 & 37 \\
Total & 3 & 24 & 46 & 35 & 108 \\
\hline
\end{tabular}

$\mathrm{TNM}=$ tumour - node - metastasis 
and clinical target volume two was $70.2 \mathrm{~Gy}$ and 54 Gy, respectively.

Eighty-eight patients $(81.5$ per cent $)$ also received cisplatin $\left(70-100 \mathrm{mg} / \mathrm{m}^{2}\right.$ on day one) plus 5 -fluorouracil (5-FU) $\left(600-1000 \mathrm{mg} / \mathrm{m}^{2}\right.$ on days one to five). Concurrent chemotherapy was given to 52 patients (48.1 per cent), neoadjuvant chemotherapy was given to 34 patients ( 31.5 per cent) and adjuvant chemotherapy was given to 24 patients ( 22.2 per cent).

\section{Follow up}

After completion of treatment, all patients were followed up every one to two months for the first two years, then every three to four months thereafter. Physical examination and laryngoscopy were performed during each follow-up examination, and a neck CT scan was done every four to six months during the first two years. For the patients who survived, the follow-up period ranged from 14 to 120 months (median 39 months).

The definition of local failure was based on the results of either the laryngoscopy or the neck CT scan, or both. If the patient had persistent tumour or locoregional recurrence following initial complete remission, salvage surgery was suggested, when it was technically feasible and the patient's condition allowed it.

\section{Statistical analysis}

Actuarial survival, disease-specific survival and local relapse-free survival were calculated using the Kaplan-Meier method. Salvage of recurrences was not taken into account in the evaluation of local relapse-free survival. Statistical significance was determined as $p<0.05$, two-tailed. Significance levels between the curves were calculated using the log-rank test. Multivariate analyses were performed using Cox's proportional hazards model.

\section{Results}

Of the 108 patients, 29 survived without known recurrent disease. Five patients had local recurrence but survived after salvage treatment. Forty-nine patients died of local recurrence alone, five patients died of distant metastasis and seven patients died due to both events. Seven patients died of treatment-related complications. Six patients died due to metachronous second malignancies (oesophagus, five; lung, one). The five-year actuarial survival and disease-specific survival rates for all patients were 25 and 30 per cent, respectively. Table III summarises the treatment outcome for all patients.

Of the 61 patients with locoregional failure, 47 developed primary tumour relapse, six were noted to have isolated neck lymph node recurrence, and eight had both primary tumour relapse and neck lymph node recurrence. Due to the severity of post-irradiation fibrosis, lack of a suitable timetable for salvage surgery and patients' refusal to undergo subsequent surgery, only 13 of these patients received salvage laryngectomy with or without neck lymph node dissection after recurrence. The
TABLE III

PATIENTS' TREATMENT RESULTS*

\begin{tabular}{lr}
\hline Result & $n$ \\
\hline Initial response & \\
Complete remission & 75 \\
Partial remission + stable disease & 33 \\
Survival status & \\
Alive, no disease & 29 \\
Alive + recurrence after salvage treatment & 5 \\
Died of disease & 61 \\
- Local relapse alone & 49 \\
- Distant metastasis alone & 5 \\
- Local relapse + distant metastasis & 7 \\
Died of complications & 7 \\
Died of secondary Ca & 6 \\
\hline
\end{tabular}

${ }^{*}$ Total $=108$ patients. ${ }^{\dagger}$ Evaluated within 3 months. $\mathrm{Ca}=$ cancer

two-year survival rates for patients with and without salvage surgery were 35 and 0 per cent, respectively $(p=0.001)$.

Figure one illustrates the survival curves according to stage. The five-year actuarial survival and diseasespecific survival rates were respectively 56 and 64 per cent for patients with stage I-II disease, 30 and 43 per cent for those with stage III disease, and 17 and 17 per cent for those with stage IVA disease. The five-year local relapse-free survival rate was 35 per cent for all patients, 66 per cent for those with stage I-II disease, 46 per cent for those with stage III disease and 20 per cent for those with stage IVA disease $(p=0.004)$. The five-year disease-specific survival rate was 60 per cent for patients with $T_{1-2}$ disease and 21 per cent for those with stage $T_{3-4}$ disease $(p=0.001)$, whereas the five-year local relapse-free survival rates for $\mathrm{T}_{1-2}$ and $\mathrm{T}_{3-4}$ disease were respectively 68 and 24 per cent $(p=0.004)$. The five-year disease-specific survival rate was 41 per cent for patients with $\mathrm{N}_{0-1}$ disease and 9 per cent for those with stage $\mathrm{N}_{2}$ disease $(p=0.005)$, whereas the five-year local relapse-free survival rates for $\mathrm{N}_{0-1}$ and $\mathrm{N}_{2}$ disease were respectively 46 and 8 per cent $(p=0.03)$. Tables IV, $\mathrm{V}$ and VI summarise the impact of the tumours and treatmentrelated parameters on actuarial survival, diseasespecific survival and local relapse-free survival in univariate and multivariate analysis.

To enable subgroup analysis of stage III disease, patients were stratified into three subgroups, as follows: group $A, T_{1} N_{1}$ and $T_{2} N_{1}$; group $B, T_{3} N_{0}$; and group $\mathrm{C}, \mathrm{T}_{3} \mathrm{~N}_{1}$. The five-year disease-specific survival rates for groups $\mathrm{A}, \mathrm{B}$ and $\mathrm{C}$ were 55,44 and 28 per cent, respectively $(p=0.35)$. The five-year local relapse-free survival rates for these same groups were 77, 31 and 37 per cent, respectively $(p=0.19)$. The disease-specific survival and local relapse-free survival curves for stage III disease, according to the above subgroups, are shown in Figure 2.

To test the effect of combined chemotherapy, a separate analysis was also performed to compare the treatment outcomes of the 95 patients with stage III-IVA lesions. The five-year disease-specific survival rates for patients with and without 
TABLE IV

UNIVARIATE AND MULTIVARIATE ANALYSIS OF PROGNOSIS FOR ACTUARIAL SURVIVAL

\begin{tabular}{|c|c|c|c|}
\hline \multirow[t]{2}{*}{ Factor } & \multicolumn{2}{|c|}{$p$} & \multirow{2}{*}{$\begin{array}{l}\text { Risk } \\
\text { ratio }\end{array}$} \\
\hline & Univariate & Multivariate & \\
\hline Age* $^{*}$ & 0.72 & & \\
\hline Performance $^{\dagger}$ & 0.07 & 0.34 & \\
\hline Trachestomy & 0.05 & 0.77 & \\
\hline Dysphagia $^{*}$ & 0.01 & 0.24 & \\
\hline T stage** & 0.001 & 0.001 & 1.70 \\
\hline N stage st $^{\S}$ & 0.01 & 0.03 & 1.34 \\
\hline Stage & 0.002 & 0.56 & \\
\hline PPW involvement & 0.30 & 0.86 & \\
\hline Larynx involvement & 0.08 & 0.44 & \\
\hline Oropharynx involvement & 0.02 & 0.32 & \\
\hline Concurrent chemo & 0.89 & & \\
\hline Neoadjuvant chemo & 0.52 & & \\
\hline Treatment duration $^{\mathrm{b}}$ & 0.17 & & \\
\hline
\end{tabular}

* $<70$ vs $\geq 70$ years; ${ }^{\dagger}$ ECOG: eastern cooperative oncology group $0-1$ vs $2-3 ;{ }^{\ddagger}$ grade $0-1$ vs $2-3 ;{ }^{* *} \mathrm{~T}_{1-2}$ vs $\mathrm{T}_{3-4} ;{ }^{\S} \mathrm{N}_{0-1}$ vs $\mathrm{N}_{2}$; ${ }^{\mathrm{a}} \mathrm{I}-\mathrm{II}-\mathrm{III} v s$ IVA; ${ }^{\mathrm{b}}<60 v s \geq 60$ days. $\mathrm{PPW}=$ posterior pharyngeal wall; chemo $=$ chemotherapy

concurrent chemotherapy were respectively 32 and 26 per cent $(p=0.57)$. The five-year local relapsefree survival rates for patients with and without concurrent chemotherapy were respectively 37 and 30 per cent $(p=0.78)$. A combination of neoadjuvant chemotherapy improved neither disease-specific survival nor local relapse-free survival. The five-year disease-specific survival rates for patients with and without neoadjuvant chemotherapy were respectively 27 and 22 per cent $(p=0.61)$. The five-year local relapse-free survival rates for patients with and without neoadjuvant chemotherapy were respectively 26 and 35 per cent $(p=0.40)$.

Multivariate analyses of actuarial survival revealed two prognostic factors: $\mathrm{T}_{1-2}$ vs $\mathrm{T}_{3-4}(p=0.001$, relative risk $1.70,95$ per cent confidence intervals $(\mathrm{CI})$ $1.21-5.67)$, and $\mathrm{N}_{0-1}$ vs $\mathrm{N}_{2}(p=0.03$, relative risk

TABLE V

UNIVARIATE AND MULTIVARIATE ANALYSIS OF PROGNOSIS FOR DISEASE-SPECIFIC SURVIVAL

\begin{tabular}{|c|c|c|c|}
\hline \multirow[t]{2}{*}{ Factor } & \multicolumn{2}{|c|}{$p$} & \multirow{2}{*}{$\begin{array}{l}\text { Risk } \\
\text { ratio }\end{array}$} \\
\hline & Univariate & Multivariate & \\
\hline Age* & 0.83 & & \\
\hline Performance $^{\dagger}$ & 0.05 & 0.26 & \\
\hline Trachestomy & 0.03 & 0.52 & \\
\hline Dysphagia & 0.004 & 0.25 & \\
\hline T stage** & 0.001 & 0.001 & 2.15 \\
\hline $\mathrm{N}_{\text {stage }}^{\S}$ & 0.005 & 0.03 & 1.47 \\
\hline Stage ${ }^{\mathrm{a}}$ & 0.001 & 0.56 & \\
\hline PPW involvement & 0.12 & 0.89 & \\
\hline Larynx involvement & 0.07 & 0.78 & \\
\hline Oropharynx involvement & 0.01 & 0.43 & \\
\hline Concurrent chemo & 0.90 & & \\
\hline Neoadjuvant chemo & 0.34 & & \\
\hline Treatment duration $^{\mathrm{b}}$ & 0.30 & & \\
\hline
\end{tabular}

$*<70$ vs $\geq 70$ years; ${ }^{\dagger}$ ECOG: eastern cooperative oncology group 0-1 vs 2-3; ${ }^{\ddagger}$ grade $0-1$ vs $2-3 ;{ }^{* *} \mathrm{~T}_{1-2}$ vs $\mathrm{T}_{3-4} ;{ }^{\S} \mathrm{N}_{0-1}$ vs $\mathrm{N}_{2} ;{ }^{\text {a }} \mathrm{I}-\mathrm{II}-\mathrm{III} v s$ IVA; ${ }^{\mathrm{b}}<60 v s \geq 60$ days. PPW $=$ posterior pharyngeal wall; chemo $=$ chemotherapy
TABLE VI

RESULTS OF UNIVARIATE AND MULTIVARIATE ANALYSIS OF PROGNOSIS FOR LOCAL RELAPSE-FREE SURVIVAL

\begin{tabular}{|c|c|c|c|}
\hline \multirow[t]{2}{*}{ Factor } & \multicolumn{2}{|c|}{$p$} & \multirow{2}{*}{$\begin{array}{l}\text { Risk } \\
\text { ratio }\end{array}$} \\
\hline & Univariate & Multivariate & \\
\hline Age* $^{*}$ & 0.37 & & \\
\hline Performance $^{\dagger}$ & 0.07 & 0.26 & \\
\hline Trachestomy & 0.01 & 0.52 & \\
\hline Dysphagia ${ }^{\ddagger}$ & 0.004 & 0.25 & \\
\hline T stage** & 0.004 & 0.02 & 2.21 \\
\hline $\mathrm{N}_{\text {stage }}^{\S}$ & 0.03 & 0.50 & \\
\hline Stage $^{\mathrm{a}}$ & 0.001 & 0.04 & 1.65 \\
\hline PPW involvement & 0.08 & 0.60 & \\
\hline Larynx involvement & 0.01 & 0.56 & \\
\hline Oropharynx involvement & 0.005 & 0.43 & \\
\hline Concurrent chemo & 0.93 & & \\
\hline Neoadjuvant chemo & 0.65 & & \\
\hline Treatment duration $^{\mathrm{b}}$ & 0.89 & & \\
\hline
\end{tabular}

$*<70 \quad v s \geq 70$ years; ${ }^{\dagger}$ ECOG: eastern cooperative oncology group $0-1$ vs $2-3 ;{ }^{*}$ grade $0-1$ vs $2-3 ;{ }^{* *} \mathrm{~T}_{1-2}$ vs $\mathrm{T}_{3-4} ;{ }^{\circledR} \mathrm{N}_{0-1}$ vs $\mathrm{N}_{2}$; ${ }^{\mathrm{a}} \mathrm{I}-\mathrm{II}-\mathrm{III} v s$ IVA; ${ }^{\mathrm{b}}<60 v s \geq 60$ days. $\mathrm{PPW}=$ posterior pharyngeal wall; chemo $=$ chemotherapy

1.34, 95 per cent CI 1.02-6.50). Multivariate analyses of disease-specific survival showed similar findings, with $\mathrm{T}_{3-4}$ tumours $(p=0.001$, relative risk $2.15,95$ per cent CI 1.25-5.42) and $\mathrm{N}_{2}$ tumours ( $p=0.03$, relative risk $1.47,95$ per cent CI 1.04-6.28) being significant. Multivariate analyses of local relapse-free survival revealed two prognostic factors: $\mathrm{T}_{1-2} v s \mathrm{~T}_{3-4}$ $(p=0.02$, relative risk $2.21,95$ per cent CI $1.21-$ $7.49)$ and stage I-II-III $v s$ stage IVA $(p=0.04$, relative risk $1.65,95$ per cent CI $1.02-6.98)$.

Of our 108 patients, 16 (14.8 per cent) had synchronous or metachronous malignancies; the anatomical sites involved included the oesophagus in 11 patients, mouth in three and lungs in two. One metachronous tongue cancer before the diagnosis of HPC was completely controlled. For four patients with synchronous oesophageal cancer, both cancers were treated with either concurrent chemoradiotherapy (three patients) or RT (one patient).

\section{Discussion}

Our data show that patients with stage I-II hypopharyngealcarcinoma (HPC) can achieve an acceptable outcome following laryngeal preservation RT. Despite our relatively small number of patients, our data are comparable with other series. ${ }^{6,7}$ Our findings show that primary RT can be the treatment of choice in terms of organ preservation, whereas surgery can be reserved for salvage in recurrent cases. The optimal irradiated field for early HPC remains controversial, due to the limited material available in our series. The retropharyngeal and supraclavicular areas were both included in our irradiated field, because of the rich lymphatic drainage to the lymph nodes at multiple levels. However, another investigator has recommended that treatment for early HPC should focus on the primary tumour and upper cervical nodes. ${ }^{8}$

Our findings also showed that HPC is often diagnosed at an advanced stage and has an aggressive 
(a)

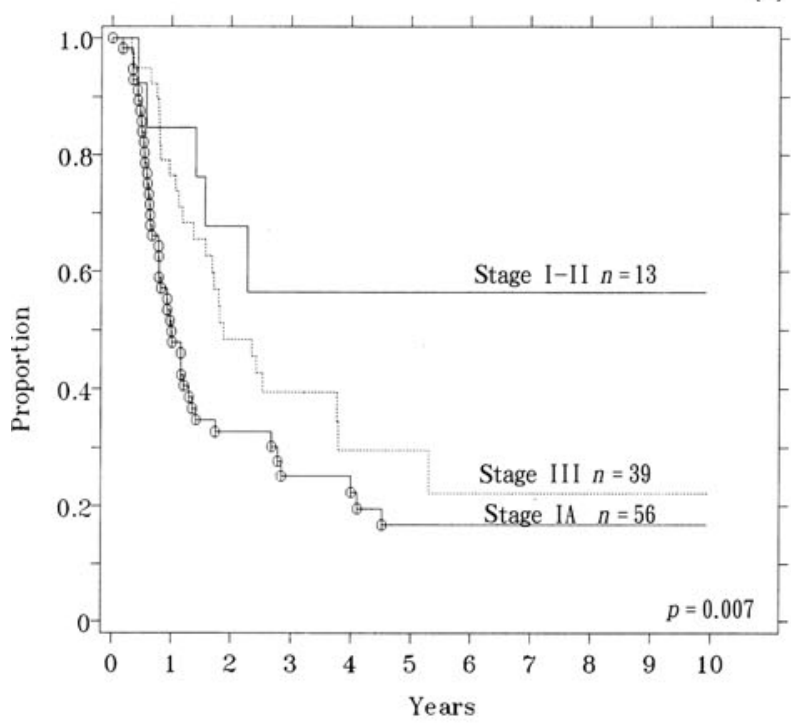

(b)

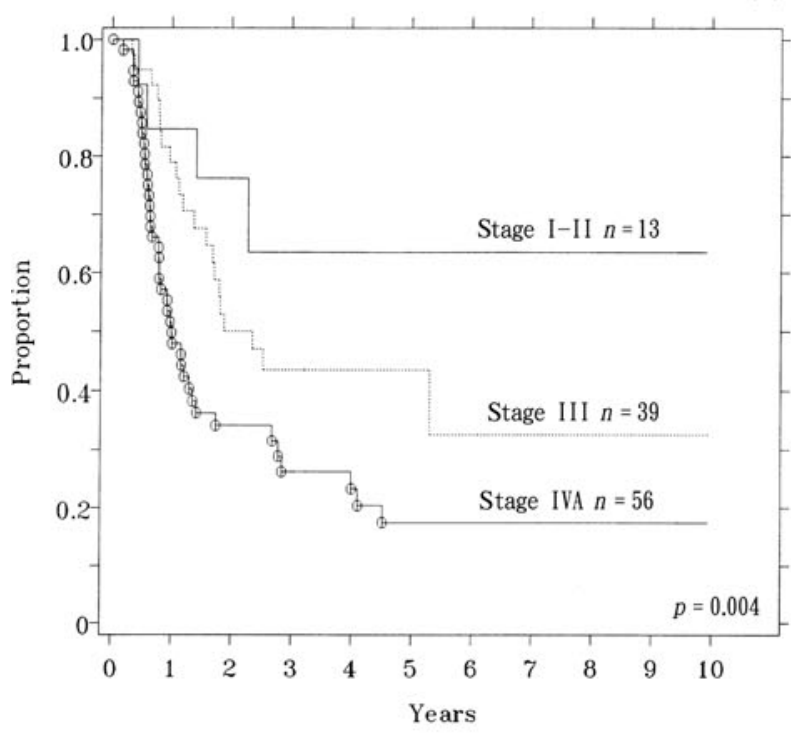

(c)

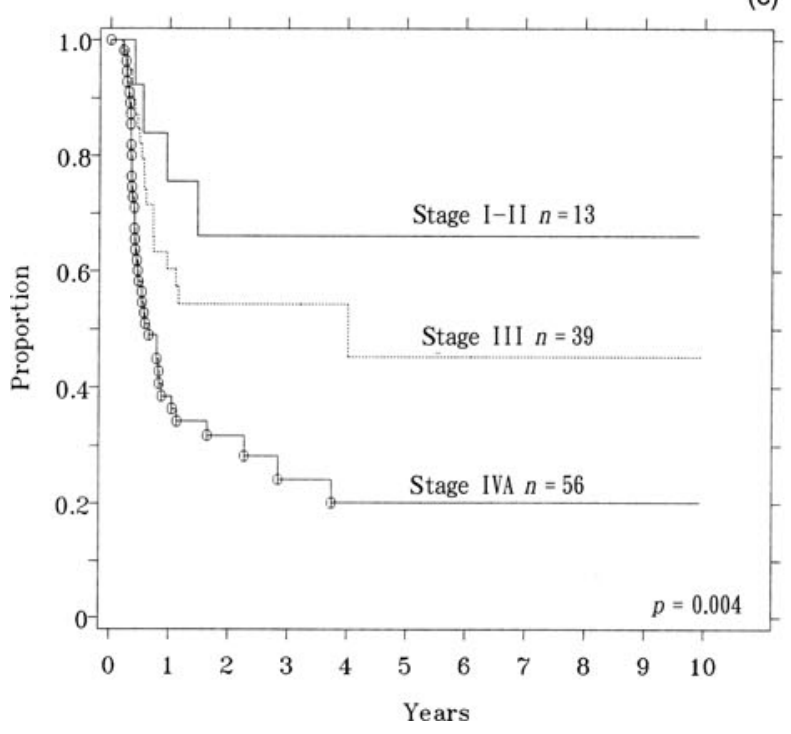

FIG. 1

Survival curves by clinical stage. (a) Actuarial survival; (b) disease-specific survival; (c) local relapse-free survival.
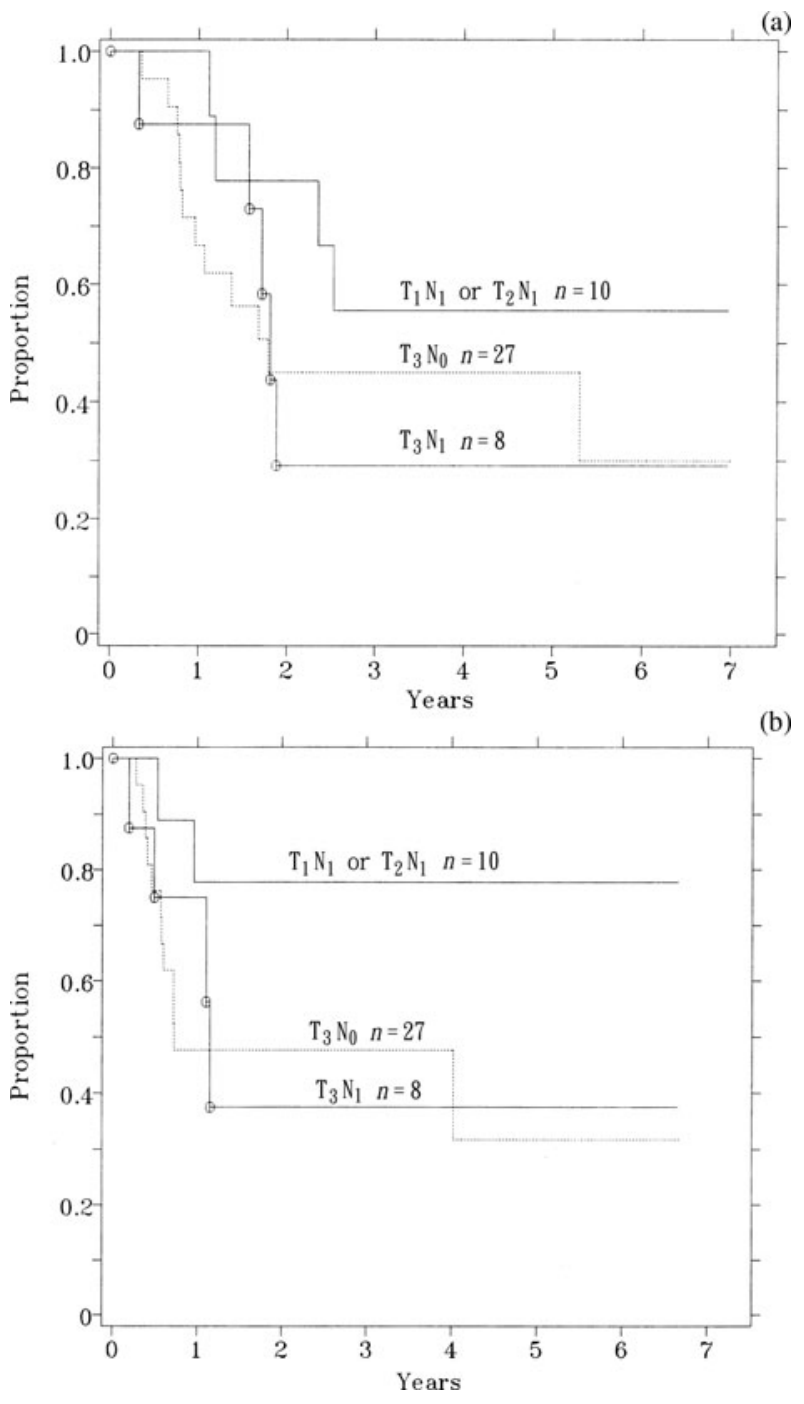

FIG. 2

Survival curves for stage III disease, by tumour-node (TN) staging subgroups. (a) Disease-specific survival; (b) local relapse-free survival.

course associated with poor prognosis. ${ }^{1,2}$ Moreover, a significant number of RT failures could not be salvaged with surgery, either because of late diagnosis or the patient's refusal to undergo subsequent surgery.

At many institutions, treatment decisions for patients with stage III-IVA disease are complex, and include such considerations as tumour location, patient condition and individual preference. In our patients, the treatment results may be ambiguous, due to the selection bias in the study. Despite the survival curves for stage III patients being higher than those for stage IVA patients, local recurrence occurred in more than half of the former cases.

Further analysis was performed in order to determine the optimal selection strategies for laryngeal preservation RT in stage III disease. The results indicated that indiscriminate use of laryngeal preservation RT in stage III HPC patients was questionable. Although the local relapse-free survival for both $T_{3} N_{0}$ and $T_{3} N_{1}$ patients was inferior when 
compared with that for $\mathrm{T}_{1} \mathrm{~N}_{1}$ and $\mathrm{T}_{2} \mathrm{~N}_{1}$ patients, this finding was constrained by the small sample size in each group. It is recommended that a further clinical trial be conducted in order to examine whether the improvement in laryngeal preservation RT outcome is more obvious in certain subgroups of patients with stage III disease. On the other hand, a review by the US National Cancer Data Base demonstrated that the decreased survival of laryngeal cancer patients in the mid-1990s might have been related to less aggressive surgery performed during this period, together with a dramatic increase in the use of chemoradiation. ${ }^{9}$ Thus, physicians should be more cautious, and it is also suggested that other prognostic factors be assessed when considering laryngeal preservation RT.

Traditional staging methods using the TNM classification have important implications for treatment choices and for the likelihood of control following definitive RT. In HPC, the clinical criteria used to classify a particular $\mathrm{T}$ category are dependent on both the site involved and the tumour diameter. Large tumour volume is known to contribute to poor local control after definitive RT, as demonstrated in some laryngeal cancer study series. ${ }^{10-12}$ As the $\mathrm{T}$ category is determined by tumour morphology, it is not surprising that tumour volumes and $\mathrm{T}$ categories are correlated to some extent. The involved sites and visible tumour diameters may be inaccurate estimations of tumour volume, because of submucosal tumour extension or invisible deep tumour extension of advanced tumours. In our previous study, ${ }^{13}$ pretreatment, CT-based tumour volumes were a strong predictor of survival and local control in patients with HPC treated with definitive RT. A selected group of patients with $T_{3-4}$ disease, mainly those with tumour volumes $<40 \mathrm{ml}$, should be considered for laryngeal preservation.

- In hypopharyngeal carcinoma patients, treatment decisions are complex and include such considerations as tumour stage and location, patient condition, and individual preference

- This study was a retrospective analysis of 108 patients with stage I-IVA squamous cell carcinoma of the hypopharynx treated with radiotherapy

- Patients with stage I-II hypopharyngeal cancer were suitable for laryngeal preservation radiotherapy

- For patients with stage III-IVA tumours, the treatment results were poor. Some effort should be made to incorporate combined modality treatment for those patients with advanced tumours

Our data show that most failures were due to primary recurrence rather than to neck failure. Of the 61 patients with locoregional failure, only six
(9.8 per cent) developed nodal recurrence alone. This might be attributed to the exclusion of $\mathrm{N}_{3}$ nodes in the study. Nevertheless, five of the six patients with distant metastases were categorised as having node-positive disease (two were $\mathrm{N}_{1}$; three were $\mathrm{N}_{2}$ ). In addition, $\mathrm{N}_{2}$ disease was also found to be an independent predictor of actuarial survival and disease-specific survival in multivariate analyses. A probable explanation is that nodal classification may be associated with total tumour volume (primary + nodal volume), which is also reflected in the probability of tumour control following laryngeal preservation radiotherapy. In the European Organization for Research and Treatment of Cancer randomised trials of advanced head and neck cancer treatment using three fractions per day and misonidazole, clinical estimation of total tumour volume was proven to be the most important independent predictor of locoregional control. ${ }^{14}$ Based on the results of our study, planned neck dissection is not warranted as part of routine care for patients with $\mathrm{N}_{0_{-1}}$ nodal disease. In contrast, $\mathrm{N}_{2}$ tumours are associated with a poor prognosis, and more aggressive, combined modality treatment should be considered.

In our study analyses, concurrent and neoadjuvant chemotherapy did not show any significant influence on survival or local control. At the time of writing, several prospective trials were investigating the role of chemotherapy in HPC treatment. An intergroup, phase III study has compared standard radiation therapy with two courses of cisplatin-based concurrent chemoradiotherapy in patients with unresectable squamous cell head and neck cancer. ${ }^{15}$ The results showed that the addition of concurrent chemotherapy significantly improved survival, although it also increased early toxicity. Even in patients with advanced HPC, Samant et al. ${ }^{16}$ demonstrated an organ preservation rate of 88 per cent using cisplatinbased concurrent chemoradiotherapy. On the other hand, several authors have utilised neoadjuvant chemotherapy in conjunction with $\mathrm{RT}$ in patients with advanced HPC in order to preserve the larynx. ${ }^{17-19}$ However, at present, the best selection criteria for HPC patients treated with neoadjuvant chemotherapy followed by definitive RT are still unknown.

In the present study, the crude incidence of synchronous and metachronous second malignancies was lower than that reported by a Japanese study. ${ }^{6}$ This might be due to pooling of advanced diseases in our series. However, the occurrence of a second cancer had little impact on actuarial survival. Careful follow up and the early detection of a second malignancy are essential, because patients with early HPC have a better prognosis.

\section{Conclusion}

More appropriate selection of patients and optimisation of laryngeal preservation treatment can be achieved. Firstly, laryngeal preservation RT should be reserved for stage I-II lesions, and careful follow up is needed in order to detect recurrence or second primaries. Secondly, indiscriminate use 
of laryngeal preservation RT for stage III disease is still problematic, because nearly half of these patients had unsuccessful outcomes. For most patients with stage III-IVA tumours, the treatment results were poor, except for $\mathrm{T}_{1} \mathrm{~N}_{1}$ and $\mathrm{T}_{2} \mathrm{~N}_{1}$ patients. Improvements in survival seem possible, via an increase in locoregional control, because distant metastases were rare. More aggressive, combined modality treatment should be considered.

\section{References}

1 Johansen LV, Grau C, Overgaard J. Hypopharyngeal squamous cell carcinoma. Treatment results in 138 consecutively admitted patients. Acta Oncol 2000;39:529-36

2 Godballe C, Jorgensen K, Hansen O, Bastholt L. Hypopharyngeal cancer: results of treatment based on radiation therapy and salvage surgery. Laryngoscope 2002;112:834-8

3 Bahadur S, Thakar A, Mohanti BK, Lal P. Results of radiotherapy with, or without, salvage surgery versus combined surgery and radiotherapy in advanced carcinoma of the hypopharynx. J Laryngol Otol 2002;116:29-32

4 Elias MM, Hilgers FJ, Keus RB, Gregor RT, Hart AA, Balm AJ. Carcinoma of the pyriform sinus: a retrospective analysis of treatment results over a 20 -year period. Clin Otolaryngol 1995;20:249-53

5 Perez CA. Uterine Cervix: Principles and Practice of Radiation Oncology, 3rd edn. Philadelphia: Lippincott-Raven, 2004;1083-8

6 Nakamura K, Shioyama Y, Kawashima M, Sato Y, Nakamura $\mathrm{N}$, Nakata $\mathrm{K}$, Hareyama $\mathrm{M}$, Takada T, Karasawa K, Watanabe T, Yorozu A, Tachibana $\mathrm{H}$, Suzuki G, Hayabuchi N, Toba T, Yamada S. Multiinstitutional analysis of early squamous cell carcinoma of the hypopharynx treated with radical radiotherapy. Int $J$ Radiat Oncol Biol Phys 2006;65:1045-50

7 Garden AS, Morrison WM, Clayman GL, Ang KK, Peters LJ. Early squamous cell carcinoma of the hypopharynx: Outcomes of treatment with radiation alone to primary disease. Head Neck 1996;18:317-22

8 Dobbs J. Hypopharynx. In: Dobbs M, Barrett A, Ash D, eds. Practical Radiation Planning, 3rd edn. London: Arnold, 1999;86-93

9 Hoffman HT, Porter K, Karnel LH, Cooper JS, Weber RS, Langer CJ et al. Laryngeal cancer in the United States: changes in demographics, pattern of care, and survival. Laryngoscope 2006;116(suppl):1-13

10 Lee WR, Mancuso AA, Saleh EM, Mendenhall WM, Parsons JT, Million RR. Can pretreatment computed tomography findings predict local control in T3 squamous cell carcinoma of the glottic larynx treated with radiotherapy alone? Int J Radiat Oncol Biol Phys 1993;25:683-7

11 Hermans R, den Bogaert WV, Rijnders A, Baert AL. Value of computed tomography as outcome predictor of supraglottic squamous cell carcinoma treated by definitive radiation therapy. Int J Radiat Oncol Biol Phys 1999;44: 755-65

12 Mancuso AA, Mukherji SK, Schmalfuss I, Mendenhall W, Parsons J, Rameijer F et al. Preradiotherapy computed tomography as a predictor of local control in supraglottic carcinoma. J Clin Oncol 1999;17:631-7

13 Chen SW, Yang SN, Liang JA, Tsai MS, Shiau AC, Lin FJ. Value of computed tomography based tumor volume as a predictor of outcomes in hypopharyngeal cancer after treatment with definitive radiotherapy. Laryngoscope 2006;116:2012-17

14 Van den Bogaert W, van der Schueren E, Horiot JC, De Vilena M, Schraub S, Svoboda V et al. The EORTC randomized trial on three fractions per day and misonidazole in advanced head and neck cancer: prognostic factors. Radiother Oncol 1995;35:100-6

15 Adelstein DJ, Li Y, Adams GL, Wagner H Jr, Kish JA, Ensley JF et al. An intergroup phase III comparison of standard radiation therapy and two schedules of concurrent chemoradiotherapy in patients with unresectable squamous cell head and neck cancer. J Clin Oncol 2003;21: $92-8$

16 Samant S, Kumar P, Wan J, Hanchett C, Vieira F, Murry T et al. Concurrent radiation therapy and targeted cisplatin chemotherapy for the treatment of advanced pyriform sinus carcinoma: disease control and preservation of organ function. Head Neck 1999;21:595-601

17 Kim KH, Sung MW, Rhee CS, Koo JW, Koh TY, Lee DW et al. Neoadjuvant chemotherapy and radiotherapy for the treatment of advanced hypopharyngeal carcinoma. Am J Otolaryngol 1998;19:40-4

18 Kraus DH, Pfister DG, Harrison LB, Shah JP, Spiro RH, Armstrong JG et al. Larynx preservation with combined chemotherapy and radiation therapy in advanced hypopharygeal cancer. Otolaryngol Head Neck Surg 1994;111: $31-7$

19 Zelefsky MJ, Kraus DH, Pfister DG, Raben A, Shah JP, Strong EW et al. Combined chemotherapy and radiotherapy versus surgery and postoperative radiotherapy for advanced hypopharyngeal cancer. Head Neck 1996;18: 405-11

Address for correspondence:

Dr Shang-Wen Chen,

Department of Radiation Therapy and Oncology,

China Medical University Hospital,

No 2 Yuh-Der Road,

Taichung, Taiwan 404.

Fax: 8864220521212499

E-mail: vincent1680616@yahoo.com.tw

Dr Shang-Wen Chen takes responsibility for the integrity of the content of the paper.

Competing interests: None declared 